Research Paper:

\title{
Relationship Between Self-Efficacy and Self-Esteem in Patients With Cancer
}

\author{
Mehdi Harorani ${ }^{1} @$, Mehdi Safarabadi ${ }^{1}$, Ali Jadidi' ${ }^{1}$, Jared Seavey ${ }^{2}$, Behnam Masmouei ${ }^{3 *} \oplus$, Mohammad Rafi Bazrafshan ${ }^{4}$
}

1. Department of Nursing, School of Nursing and Midwifery, Arak University of Medical Sciences, Arak, Iran.

2. School of Nursing, College of Health Sciences, Walden University, Minneapolis, United States.

3. Department of Nursing, Abadeh Branch, Islamic Azad University, Abadeh, Iran.

4. Department of Nursing, School of Nursing, Larestan University of Medical Sciences, Larestan, Iran.

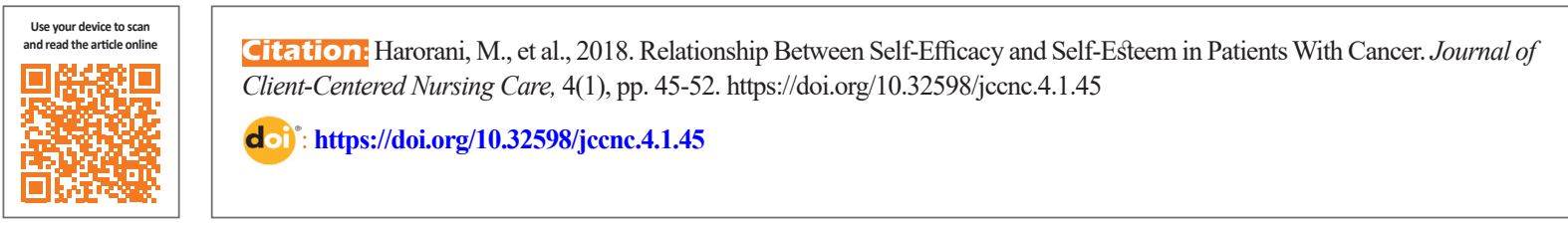

Funding: See Page 49

(c) Copyright: The Author(s)

Article info:

Received: 05 Jul 2017

Accepted: 20 Nov 2017

Available Online: 01 Feb 2018

Keywords:

Self-esteem, Self-efficacy,

Cancer

\section{A B S T RA C T}

Background: Given the negative impact of cancer on the quality of life, low self-efficacy and self-esteem are common in the patients suffering from cancer. This study aims to determine the relationship between self-efficacy and self-esteem in these patients.

Methods: This study was descriptive and cross-sectional and was conducted in Ayatollah Khansari Hospital in Arak. The obtained data were collected from 160 eligible patients diagnosed with cancer using Coopersmith self-esteem inventory and the strategies used by people to promote health and then analyzed in SPSS V. 20.

Results: Spearman correlation showed a significant relationship between the subscales and the total score of self-efficacy and self-esteem score $(\mathrm{P}<0.05)$. Also, linear regression analysis revealed that self-efficacy could significantly predict self-esteem $(\mathrm{P}<0.05)$.

Conclusion: Self-efficacy had a direct relationship with self-esteem. By improving self-efficacy, self-esteem will increase and lead to more self-care compliance and initiative in cancer patients.

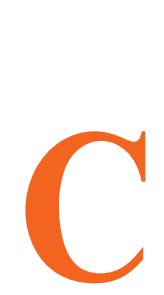

\section{Background}

ancer has become a major public health problem worldwide and is the second leading cause of death in the United States (Siegel, Miller \& Jemal 2016). With continued development in cancer diagnosis and treatment, patients now have blessed with early diagnosis resulting in effective treatment plans and better outcomes, sustained periods of remission, and prolonged life. However, evidence has shown problems with psycho- logical adjustment and worsening of Quality of Life (QoL) in these patients (Mishra et al. 2017). Increase in the survival rate of patients with cancer accompanies with distress symptoms such as fatigue, pain, anxiety, depression, loss of control, helplessness, severe emotional distress, decreased self-esteem and cognitive problems in daily activities (Holland \& Alici 2010; López, López Roig \& Pastor 2007).

Given that cancer is a chronic disease with potential acute complications, the patients experience different medical interventions specific to their diagnoses. For example, some

\section{* Corresponding Author:}

Behnam Masmouei, MSc

Address: Department of Nursing, Abadeh Branch, Islamic Azad University, Abadeh, Iran

Tel: +98 (917) 9520084

E-mail: behnam.masmouei@gmail.com 
individuals may experience surgical intervention, chemotherapy, or radiotherapy throughout the course of their illness. Even though these treatments are effective and pertinent to their diagnosis and overall outcome, complications may arise that could be life-threatening. The nature of cancer is pathologically vigorous. Patients may encounter a variety of problems that could potentially interfere with their natural process of life and harms their self-efficacy and self-esteem. Therefore, efforts to restore the physical and mental health of these patients are of great value (Awick et al. 2017).

Self-efficacy is considered as one of the major components towards developing a successful self-management practice throughout a chronic disease. Research has shown that self-efficacy beliefs affect many aspects of personal performance (Maddux 2016). An individual's confidence, or belief in his strength, is a prerequisite for performing any task as it influences the maintenance of healthy behaviors (Gallagher et al. 2008). Those who have higher levels of self-efficacy express better physical and mental health than those who possess less. Appreciation of personal values may awaken the patient of his current health status while supporting the treatment protocol.

Self-efficacy signifies self-confidence in his abilities across a wide range of demanding situations and reflects a person's general problem-solving ability (van de Wiel, Geerts \& Hoekstra Weebers 2008). A positive perception of self-worth can help cancer patients engage in coping with burden and stress of the disease (Chirico et al. 2017). Previous studies have shown significant associations between higher self-efficacy and physical health (Schwarzer 1993), better mental and physical health-related quality of life (Robb et al. 2013), increased physical functioning (Phillips \& McAuley 2014), and increased QoL in patients with cancer (Haugland et al. 2016).

The current cancer treatment methods could harm patient's self-esteem and exerts negative pressure on his body image (Kim et al. 2012). For example, self-esteem often declines following a cancer-related diagnosis. Due to the national stigma associated with the term of cancer, the public tends to view cancer unappealing. This may partly be due to the physical changes from surgery and chemotherapy including scarring, hair loss, and cachexia or weight loss. However, the ideation behind shaping self-esteem in a positive manner has been identified as an important factor influencing health-related QoL and well-being, allowing survivors to thrive after diagnosis and treatment (Koch et al. 2017).

Numerous studies have indicated that diagnosis of cancer may harm self-efficacy and self-esteem. However, the relationship between self-esteem and self-efficacy in cancer patients has not been clearly explored. The primary focus of this study was determining the interrelation of these variables. The correlation between these variables could benefit the treatment and outcomes of cancer patients during their rehabilitative process.

\section{Materials and Methods}

\section{Study design and sample}

In 2015, we conducted a descriptive, cross-sectional study on 160 cancer patients referring to the Hematology or Oncology departments of Ayatollah Khansari Hospital in Arak, Iran. The samples were selected by convenience sampling method. Patients with different types of cancer that met the inclusion criteria were selected. The inclusion criteria comprised patients' literacy, aged 30-60 years, at least 6 months past their cancer diagnosis, no history of underlying mental illness, seizure, or heart disease, and a stage of cancer greater than or equal to two. The sample size based on $5 \%$ type I error and the $80 \%$ power was estimated by previous study (Qian \& Yuan 2012).

\section{Study measures}

Self-efficacy was measured by a standard questionnaire of Strategies Used by People to Promote Health (SUPPH). Validity and reliability of this tool have been confirmed in various studies (Eller et al. 2016; Qian \& Yuan 2012), including Iran; so that its internal consistency has been reported by calculating Cronbach $\alpha$ as 0.94 (Fini, AdibHajbaghery \& Khachian 2011). The 29-item questionnaire is scored by Likert type scale ranging from 5 "full confidence" to 1 "very little confidence". The test has three subscales of "breakdown of adaptability", "stress reduction", and "decision making" of self-efficacy. The total score of this questionnaire would be 145 points, while gaining higher scores indicate higher self-efficacy.

A standard tool of measurement designed specifically by Cooper Smith was applied to distinguish adult attitudes towards oneself in order to comprehend an individualistic approach to a patient's personal view of his self-esteem (Boyes et al 2017; Matthews, Grunfeld \& Turner 2017). The method of scoring for the Coopersmith Self-Esteem Inventory (CSEI) is 0 or 1 ; so that 0 means that the answer is wrong and 1 refers to the correct answer.

The overall self-esteem score is obtained by summing scores of four subscales of "general", "family", "social", and "occupational or educational" domain. The maximum score on general domain is equal to 26 , and in each of the three other domains is equal to 8 . The maximum total self- 
esteem score is 50. Validity and reliability of CSEI have been confirmed in previous studies ( $\mathrm{r}=92 \%$ ) (Hemati et al. 2017). In addition, Delaram et al. estimated the reliability of this tool as 93\% (Delaram et al. 2012). The questionnaires were delivered to the patients at the time of discharge. The collected data were analyzed using Spearman correlation, and regression in SPSS V. 20.

\section{Results}

Most of the samples were male (51.3\%) and the majority of them $(73.7 \%)$ were older than 50 years. Table 1 presents the demographic data of the participants. Based on the Kol-
mogorov-Smirnov test, the self-efficacy and self-esteem score had nonparametric distributions $(\mathrm{P}=0.005, \mathrm{P}=0.008$, respectively). The relationships between demographic variables with self-efficacy and self-esteem were analyzed using the Chi-square test (Table 2). The intensity of the relationship was determined by Cramer's V test.

According to Spearman correlation test there was a significant relationship between the total score of self-efficacy and an individual's cancer stage $(\mathrm{r}=-0.282, \mathrm{P}=0.000)$ and also between self-esteem and an individual's cancer stage $(\mathrm{r}=-0.213, \mathrm{P}=0.007)$. The relationship between patient's age, self-efficacy, and self-esteem score was measured us-

Table 1. Demographic characteristics of the study subjects

\begin{tabular}{|c|c|c|}
\hline \multicolumn{2}{|c|}{ Variable } & \multirow{2}{*}{$\begin{array}{c}\text { No. (\%) } \\
82(51.3)\end{array}$} \\
\hline Cor & Male & \\
\hline sex & Female & $78(48.7)$ \\
\hline \multirow{3}{*}{ Age range (y) } & $30-40$ & $10(6.3)$ \\
\hline & $41-50$ & $32(20)$ \\
\hline & $51-60$ & $118(73.7)$ \\
\hline \multirow{3}{*}{ Marital status } & Single & $2(1.3)$ \\
\hline & Married & $148(92.5)$ \\
\hline & Widow & $10(6.2)$ \\
\hline \multirow{4}{*}{ Occupation } & Unemployed & $6(3.8)$ \\
\hline & Retired & $12(7.5)$ \\
\hline & Employed & $94(58.7)$ \\
\hline & Housewife & $48(30)$ \\
\hline \multirow{4}{*}{ Education } & Elementary & $44(27.5)$ \\
\hline & Secondary school & $68(42.5)$ \\
\hline & Diploma & $30(18.8)$ \\
\hline & Academic degree & $18(11.2)$ \\
\hline \multirow[t]{2}{*}{ Location } & Urban & $120(75)$ \\
\hline & Rural & $40(25)$ \\
\hline \multirow{7}{*}{ Cancer } & Liver and pancreas & $10(6.3)$ \\
\hline & Respiratory system & $16(10)$ \\
\hline & Digestive system & $32(20)$ \\
\hline & Urinary and genital system & $14(8.7)$ \\
\hline & Breast & $30(18.8)$ \\
\hline & Lymphoma & $40(25)$ \\
\hline & Brain & $18(11.2)$ \\
\hline \multirow{2}{*}{ Cancer stage } & II & $92(57.5)$ \\
\hline & III & $68(42.5)$ \\
\hline \multirow{4}{*}{ Treatment } & Chemotherapy & $48(30)$ \\
\hline & Radiotherapy & $4(2.5)$ \\
\hline & Surgery & $4(2.5)$ \\
\hline & Hybrid & $104(65)$ \\
\hline
\end{tabular}

Client- Centered Nursing Care 
Table 2. Pearson correlation between self-esteem and self-efficacy subscales

\begin{tabular}{|c|c|c|c|c|c|c|c|c|}
\hline \multirow{2}{*}{ Self-Efficacy } & \multicolumn{2}{|c|}{ Coping } & \multicolumn{2}{|c|}{ Reduction of Stress } & \multicolumn{2}{|c|}{ Decision Making } & \multicolumn{2}{|c|}{ Total Score } \\
\hline & $\mathbf{P}$ & $\mathbf{R}$ & $\mathbf{P}$ & $\mathbf{R}$ & $\mathbf{P}$ & $\mathbf{R}$ & $\mathbf{P}$ & $\mathbf{R}$ \\
\hline General self-esteem & $<0.001$ & 0.566 & $<0.001$ & 0.623 & $<0.001$ & 0.452 & $<0.001$ & 0.761 \\
\hline Social self-esteem & $<0.001$ & 0.509 & $<0.001$ & 0.476 & $<0.001$ & 0.586 & $<0.001$ & 0.679 \\
\hline Family self-esteem & $<0.001$ & 0.559 & $<0.001$ & 0.348 & $<0.001$ & 0.587 & $<0.001$ & 0.662 \\
\hline Job self-esteem & $<0.001$ & 0.490 & $<0.001$ & 0.445 & $<0.001$ & 0.548 & $<0.001$ & 0.645 \\
\hline Total score & $<0.001$ & 0.622 & $<0.001$ & 0.599 & $<0.001$ & 0.591 & $<0.001$ & 0.816 \\
\hline
\end{tabular}

ing the Spearman test, which was respectively $(\mathrm{r}=-0.307$, $\mathrm{P}=0.000),(\mathrm{r}=-0.262, \mathrm{P}=0.001)$.

The Spearman correlation illustrated a significant relationship between self-esteem and self-efficacy $(\mathrm{r}=0.816$, $\mathrm{P}<0.05$ ) (Figure 1). Also according to Spearman correlation test, there was a significant relationship between the subscales of self-efficacy and self-esteem (Table 2). Regression analysis showed that self-efficacy and its subscales have the ability to predict self-esteem (Table 3 ).

\section{Discussion}

In many studies, the relationship between self-efficacy and various variables have been investigated, but there are few studies on the relationship between self-efficacy and self-esteem. For example, one study found a significant relationship between self-efficacy and academic performance (Lane, Lane \& Kyprianou 2004). The relationship between self-efficacy and quality of life has also been identified in some studies (Kiaei et al. 2016; Mudrak et al. 2016; Yeung \& Lu 2014). In another study, the positive effect of self-efficacy on postsurgical complications in lung cancer was addressed (Hoffman et al. 2017). Increasing self-efficacy in the caregivers of hospitalized cancer patients has been proven to reduce cancer symptoms as well as caregivers' stress for their practice (Hendrix et al. 2016).
In a recent study, evidence indicates a significant relationship between self-efficacy and marital/employment status resulted more social interaction between family and coworkers. This result was also reported by Akin study (Akin \& Guner 2017).

Many studies have also been done about the impact of self-esteem on various variables. The positive impact of self-esteem on the QoL of children with malocclusion and orthodontics has been investigated (Clijmans et al. 2015; Dimberg et al. 2016). Also, self-esteem has increased resilience towards family dysfunction (Fontaine et al. 2017).

Even a meta-analysis study showed that an increase in self-esteem can reduce depression symptoms (Sowislo \& Orth 2013). It has been shown that self-esteem is associated with a better state of mind/behavior and physical activity among breast cancer survivors (Karamouzis et al. 2016). Furthermore, a study based on subjects with cervical cancer demonstrate that survivors with low self-esteem and social support tend to have a lower QoL than those with low selfesteem and a higher social support system (Li et al. 2015).

Another study reports a reduction of self-esteem among cancer patients when they are experiencing episodes of severe pain, higher levels of depression, increased feelings of hopelessness, and active suicidal ideation (Ozdemiroglu

Table 3. Self-efficacy and its subscales regression models for predicting total self-esteem score

\begin{tabular}{ccccccc}
\hline & \multicolumn{5}{c}{ Total Self-Esteem Score } \\
\cline { 2 - 6 } Self-Efficacy Domains & $\mathbf{R}^{2}$ & $\mathbf{F}$ & $\mathbf{B}$ & $\boldsymbol{\beta}$ & $\mathbf{P}$ \\
\hline Coping & 0.387 & 99.77 & 0.394 & 0.622 & $<0.001$ \\
Reduction of stress & 0.358 & 88.23 & 0.670 & 0.599 & $<0.001$ \\
Decision making & 0.349 & 84.81 & 1.72 & 0.591 & $<0.001$ \\
Total score of self-efficacy & 0.666 & 314.71 & 0.387 & 0.816 & $<0.001$ \\
\hline
\end{tabular}




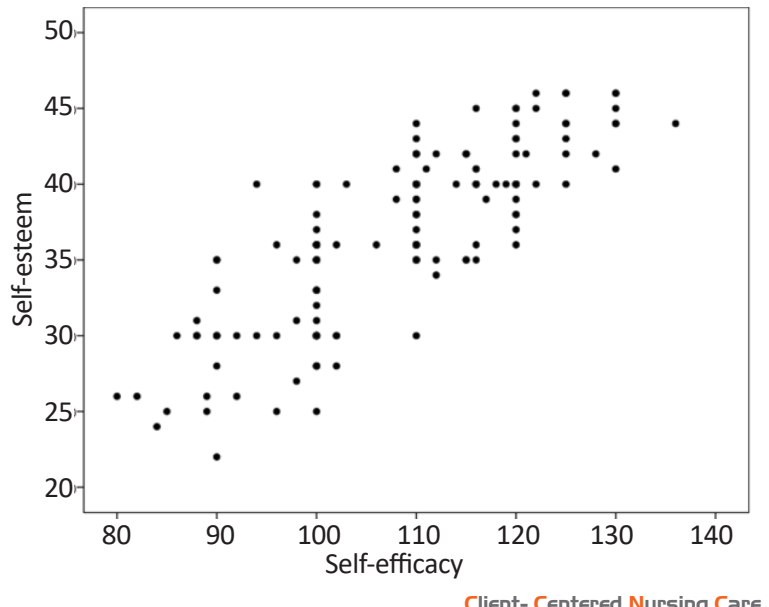

Figure 1. Scatter graph of correlation between self-esteem and self-efficacy

et al. 2017). All of these studies have focused on the importance of self-esteem in patients. Thus when self-esteem plays such an important role for cancer patients, it is advisable to examine the potential factors that could alter it.

Numerous studies have not been completed or even initiated to discuss the relationship between self-efficacy and self-esteem, particularly in cancer patients. In accordance with an alternative study, it has been shown that increasing self-esteem in a scientific and/or academic environment may increase self-efficacy and academic achievement of professors (Orczyk 1990). A study also found that parents' level of self-efficacy could provide a major impact on their children's self-esteem (Choe 2009). All of these articles and studies can relate to the results found within this research.

\section{Clinical implications}

One of the most important goals of clinical care in chronic diseases such as cancer is to provide a safe, calm, and comfortable atmosphere for the patients while embracing and exploiting positive self-esteem and self-efficacy practice in them. The findings of this study indicate a direct relationship between self-efficacy and self-esteem. In retrospect, if health care personnel were to combine their efforts towards increasing self-efficacy in their patients by reinforcing autonomy, open communication techniques, and support, self-esteem would gradually escalate over time. Also by increasing the self-efficacy of patients, their quality of life will improve as well, which is the ultimate goal of health care system.
Self-efficacy has a direct relationship with self-esteem. According to the results of this study, self-esteem has the ability to increase in correlation with rising selfefficacy levels. This in turn leads to increased QoL and treatment efficiency in patients with cancer. According to the study results, it is suggested that the relationship between self-efficacy and self-esteem with other symptoms and complications of cancer, such as fatigue, pain, nausea, stress, anxiety, depression, etc. be examined.

Our study limitations consisted of failure to mental health evaluation and its effects on cancer, considering drug and alcohol abuse, and finally comparing patient's compliance and cooperative behavior with those being non-compliant and unwilling throughout the study until completion. In future studies it is suggested that other factors that affect self-efficacy of patients be addressed. Also, the effect size of different factors could be considered.

\section{Ethical Considerations}

\section{Compliance with ethical guidelines}

This study was approved with the research code of 2223 from Arak Medical University Research Council and the Code of Ethics in Medical Research, IR.ARAKMU. REC.1394.79. In addition to obtaining written consent, this study attempted to observe the provisions of ethical codes related to research and in particular respect for the freedom of individuals to refuse to continue studying and confidentiality of all personal information.

\section{Funding}

This research was funded by Arak University of Medical Sciences.

\section{Conflict of interest}

The authors declared no conflict of interest.

\section{Acknowledgements}

We are grateful to everyone, including the family of patients and all the officials who collaborated on the implementation of this study. 


\section{References}

Akin, S. \& Guner, C. K., 2017. Determinants of fatigue, self-efficacy, and quality of life of cancer patients during chemotherapy: A study from Turkey. Journal of Nursing Science, 3(4), pp. 17-26.

Awick, E. A., et al., 2017. Physical activity, self-efficacy and selfesteem in breast cancer survivors: A panel model. Psycho-Oncology, 26(10), pp. 1625-31. [DOI:10.1002/pon.4180] [PMID]

Boyes, M. E., et al., 2017. Relationships between reading ability and child mental health: Moderating effects of self-esteem. Australian Psychologist, 53(2), pp. 125-33. [DOI:10.1111/ap.12281]

Chirico, A., et al., 2017. Self-efficacy for coping moderates the effects of distress on quality of life in palliative cancer care. Anticancer Research, 37(4), pp. 1609-15. [DOI:10.21873/anticann res.11491] [PMID]

Choe, H. S., 2009. [The mediational role of parenting self-efficacy and behavior on child self-esteem: Female international marriage immigrant and Korean mothers (Korean)]. Korean Journal of Child Studies, 30(5), pp. 245-62.

Clijmans, M., et al., 2015. Impact of self-esteem and personality traits on the association between orthodontic treatment need and oral health-related quality of life in adults seeking orthodontic treatment. European Journal of Orthodontics, 37(6), pp. 643-50. [DOI:10.1093/ejo/cju092] [PMID]

Delaram, M., et al., 2012. [Comparison of general health in droupout and Non-droupout students of Shahrekord University of Medical Sciences (Persian)]. Scientific Journal of Ilam University of Medical Sciences, 20(2), pp. 1-8.

Dimberg, L., et al., 2016. Oral health-related quality-of-life among children in Swedish dental care: The impact from malocclusions or orthodontic treatment need. Acta Odontologica Scandinavica, 74(2), pp. 127-33. [PMID]

Eller, L. S., et al., 2016. Describing self-care self-efficacy: Definition, measurement, outcomes, and implications. In ternational Journal of Nursing Knowledge, 29(1), pp. 38-48. [DOI:10.1111/2047-3095.12143] [PMID]

Fini, I. A., Adib Hajbaghery, M. \& Khachian, A., 2011. [The effect of health-promotion strategies education on self-care self-efficacy in patients with bone marrow transplantation (Persian)]. Iranian Journal of Critical Care Nursing, 4(3), pp. 109-16.

Fontaine, C., et al., 2017. The impact of emotional acknowledgement and self-esteem on resilience to family dysfunction. European Psychiatry, 41(Suppl), pp. S734-5. [DOI:10.1016/j. eurpsy.2017.01.1346]

Gallagher, R., et al., 2008. Self-management in older patients with chronic illness. International Journal of Nursing Practice, 14(5), pp. 373-82. [DOI:10.1111/j.1440-172X.2008.00709.x] [PMID]

Haugland, T., et al., 2016. Association between general self-efficacy, social support, cancer-related stress and physical healthrelated quality of life: A path model study in patients with neuroendocrine tumors. Health and Quality of Life Outcomes, 14(1) p. 11. [DOI:10.1186/s12955-016-0413-y] [PMID] [PMCID]

Hemati, Z., et al., 2017. The effect of happiness training on selfesteem in the mothers of children with cleft lip and palate in Isfahan 2015. Journal of Education and Health Promotion, 6, p. 68. [PMID] [PMCID]
Hendrix, C. C., et al., 2016. Effects of enhanced caregiver training program on cancer caregiver's self-efficacy, preparedness, and psychological well-being. Supportive Care in Cancer, 24(1), pp. 327-36. [DOI:10.1007/s00520-015-2797-3] [PMID] [PMCID]

Hoffman, A. J., et al., 2017. Using perceived self-efficacy to improve fatigue and fatigability in postsurgical lung cancer patients: A pilot randomized controlled trial. Cancer Nursing, 40(1), pp. 1-12. [DOI:10.1097/NCC.0000000000000378] [PMID] [PMCID]

Holland, J. C. \& Alici, Y., 2010. Management of distress in cancer patients. The Journal of Supportive Oncology, 8(1), pp. 4-12. [PMID]

Karamouzis, M., et al., 2016. Association between physical activity, psychological mood profile and self-esteem among breast cancer survivors. Annals of Oncology, 27(suppl_6), p. 305. [DOI:10.1093/annonc/mdw365.84]

Kiaei, M., et al., 2016. [Association between self-efficacy and quality of life in women with breast cancer undergoing chemotherapy (Persian)]. The Journal of Qazvin University of Medical Sciences, 20(2), pp. 58-65.

Kim, S., et al., 2012. Effects of cancer-overcome BeHaS exercise program on shoulder external rotation, cancer coping and group cohesion in mastectomy patients. Journal of Muscle and Joint Health, 19(3), pp. 319-28. [DOI:10.5953/ JMJH.2012.19.3.319]

Koch, A. K., et al., 2017. The effects of yoga and self-esteem on menopausal symptoms and quality of life in breast cancer survivors: A secondary analysis of a randomized controlled trial. Maturitas, 105, pp. 95-9. [DOI:10.1016/j.maturir tas.2017.05.008] [PMID]

Lane, J., Lane, A. M. \& Kyprianou, A., 2004. Self-efficacy, selfesteem and their impact on academic performance. Social Behavior and Personality: An International Journal, 32(3), pp. 247-56. [DOI:10.2224/sbp.2004.32.3.247]

Li, C. C., et al., 2015. Social support buffers the effect of self-esteem on quality of life of early-stage cervical cancer survivors in Taiwan. European Journal of Oncology Nursing, 19(5), pp. 48694. [DOI:10.1016/j.ejon.2015.02.008] [PMID]

López, M. C. N., López Roig, S. \& Pastor, M. Á., 2007. Control beliefs in cancer: A literature review. Anuario de psicología/The UB Journal of Psychology, 38(3), pp. 333-55.

Maddux, J. E., 2016. Self-efficacy interpersonal and intrapersonal expectancies. Abingdon: Routledge.

Matthews, H., Grunfeld, E. A. \& Turner, A., 2017. The efficacy of interventions to improve psychosocial outcomes following surgical treatment for breast cancer: A systematic review and meta-analysis. Psycho-Oncology, 26(5), pp. 593-607. [DOI:10.1002/pon.4199] [PMID]

Mishra, S. I., et al., 2017. Abstract B24: Health related quality of life during cancer treatment: Perspectives of adolescent and young adult cancer patients and caregivers. Cancer Epidemiology Biomarkers \& Prevention, 26(2 Suppl), p. B24. [DOI:10.1158/1538-7755.DISP16-B24]

Mudrak, J., et al., 2016. Physical activity, self-efficacy, and quality of life in older Czech adults. European Journal of Ageing, 13(1) pp. 5-14. [DOI:10.1007/s10433-015-0352-1] [PMID] [PMCID] 
Orczyk, C. L. B., 1990. A model of faculty socialization: Critical career events, self-esteem and their effect on self-efficacy and scholarly achievement [PhD dissertation]. Michigan: University of Michigan.

Ozdemiroglu, F., et al., 2017. Self-esteem, pain and suicidal thoughts in a sample of cancer patients. Journal of Mood Disorders, 7(3), pp. 156-62. [DOI:10.5455/jmood.20170804091851]

Phillips, S. M. \& McAuley, E., 2014. Physical activity and quality of life in breast cancer survivors: The role of self-efficacy and health status. Psycho-Oncology, 23(1), pp. 27-34. [DOI:10.1002/ pon.3366] [PMID] [PMCID]

Qian, H. \& Yuan, C., 2012. Factors associated with selfcare self-efficacy among gastric and colorectal cancer patients. Cancer Nursing, 35(3), pp. E22-E31. [DOI:10.1097/ NCC.0b013e31822d7537] [PMID]

Robb, C., et al., 2013. Health and personal resources in older patients with cancer undergoing chemotherapy. Journal of Geriatric Oncology, 4(2), pp. 166-73. [DOI:10.1016/j.jgo.2012.12.002] [PMID] [PMCID]

Schwarzer, R., 1993. Measurement of perceived self-efficacy: Psychometric scales for cross-cultural research. Berlin: Free University of Berlin, Institute for Psychology.

Siegel, R. L., Miller, K. D. \& Jemal, A., 2016. Cancer statistics, 2016. CA: A Cancer Journal for Clinicians, 66(1), PP. 7-30. [DOI:10.3322/caac.21332]

Sowislo, J. F. \& Orth, U., 2013. Does low self-esteem predict depression and anxiety? A meta-analysis of longitudinal studies. Psychological Bulletin, 139(1), pp. 213-40. [DOI: 10.1037/ a0028931] [PMID]

Van de Wiel, H., Geerts, E. \& Hoekstra-Weebers, J., 2008. Explaining inconsistent results in cancer quality of life studies: The role of the stress-response system. Psycho-Oncology, 17(2), pp. 174-81. [DOI:10.1002/pon.1214] [PMID]

Yeung, N. \& Lu, Q., 2014. Affect as a mediator between self-efficacy and quality of life among Chinese cancer survivors in China. European Journal of Cancer Care, 23(1), pp. 149-55. [DOI:10.1111/ecc.12123] [PMID] 
February 2018. Volume 4. Number 1

Client-Centered Nursing Care

52 